\title{
The Issues of Cryojet Technology Application for Rock Cutting
}

\author{
Konstantin Golovin ${ }^{1, *}$, Roman Kovalev ${ }^{1}$, and Andrey Kopylov ${ }^{1}$ \\ ${ }^{1}$ Tula State University, Lenin avenue 90 , Tula, Russia
}

\begin{abstract}
Water-jet technologies, based on the use of high-speed jets as cutting tools, are one of the promising directions of the destruction technologies for various materials. Jets' capability to cut even very strong, anisotropic and composite materials, as well as their high cutting speed, that can be reached without workpiece reaction occurring on the tool, make them attractive from the point of view of their implementation as cutting tools. This paper outlines the methods of materials destruction by means of high-speed cryojet and discusses future areas of its application. The research reveals the main factors and criteria for evaluating the effectiveness of cryojet cutting. Experimental studies of the main factors affecting the cryojet cutting parameters were carried out using a bench unit. As a result of the experimental data analysis, we found the correspondences that can be used for calculating the cryojet cutting of various materials.
\end{abstract}

\section{Introduction}

At present, there are several advanced destruction methods that involve using high-speed jets, such as cryojet cutting.

Cryojet (a cold water-jet saturated with ice particles) has a combined effect on the material, consisting in simultaneous action of tension-compression occurring due to the hydraulic jet component and that of erosive destruction due to the accelerated ice particles, and these effects take place against the backdrop of complex thermodynamic phenomena, the description of which is highly desirable for understanding the physical essence of the cutting process.

\section{Materials and Methods}

Special methods for cutting solid objects (using ultrasound, electrochemical methods, plasma, superheated steam, etc.) that are currently used have significant drawbacks, the main ones of which include high cost of equipment, feasibility of cutting only a certain type of material, limited depth of cut, etc.

The use of laser cutting for materials with synthetic fibers causes the joining of layers due to the fusion of cuts, and their burning causes deterioration of the sanitary and hygienic

\footnotetext{
* Corresponding author: kagolovin@mail.ru
} 
working conditions and the environment. At the same time, increased gas contamination and dustiness reduces labor productivity and the quality of products, causes enterprise staff turnover and leads to resignations in $9.3 \%$ of cases [1].

Currently, hydraulic and hydroabrasive cutting of rocks and other strong materials has been widely studied in theory and comprehensively investigated with experiments.

The use of water-jet cutting technology helps eliminate the shortcomings typical for traditional cutting methods.

In most cases untreated water and water with abrasive additives is used as a working fluid in the hydraulic cutting of materials.

The use of untreated water as a working fluid that is readily available, has a low cost, is not toxic and is justified for cutting low-strength materials. The main drawback of its use is the need to create very high jet pressures to cut strong materials, and also there are some limitations concerning the thickness of the materials being processed. When manufacturing hydraulic cutting equipment with high working fluid pressure (up to $10,000 \mathrm{MPa}$ ), when it is possible to use untreated water to cut almost any kind of materials, its designing and operation becomes more complicated. Thus, the main problem is connected with the use of seals made of special materials that have a limited durability, and also with the use of highstrength steels and alloys for the manufacturing of high-pressure units of hydro-cutting equipment. The cost of such equipment is quite high while the durability is limited. Another disadvantage of using untreated water in watercutting is the inability to provide the required productivity and cutting quality (cutting precision and width, quality of the treated surfaces), when processing materials with high physical and mechanical characteristics and thickness. The reason for this is the low hydrodynamic parameters of the jet, which has a large spray area and low stability, which affects its destruction capability. Thus, the drawbacks described above limit the application of the untreated water as a working fluid in hydraulic cutting.

One of the ways to increase the productivity of hydrocutting process, that extends its technological capabilities, is to put abrasive additives into the cutting jet. This allows cutting of high-strength materials, including steels, at relatively low pressures of 250-500 $\mathrm{MPa}$, while ensuring the same productivity as when cutting with clean water at a higher flow pressure.

Cutting and processing of materials require using hydropower plants with a power of 8$80 \mathrm{~kW}$, which provide a jet flow pressure of 150-1000 MPa and higher, which corresponds to a jet speed of $540-1400 \mathrm{~m} / \mathrm{s}$ and significantly exceeds the speed of sound in air.

\section{Results and Discussion}

Cryojet processing for paint removal was first studied by Defense Research Establishment Pacific in the late 1960s - early 1970s. First experiments showed that it was possible to accelerate ice particles with air under high pressure. A more thorough study of the influence of ice particles' size, temperature, flow, distance to the treated surface and pressure, was carried out by Vickers et al. and showed that cryojet treatment could be used to remove a variety of coatings from metal surfaces.

The findings of the papers [2] allowed us to determine the areas of perspective application of cryojets:

- surface cleaning,

- disinfection,

- cutting of materials of different strength,

- cutting of explosives,

- medicine (surgery). 
The analysis of the published researches proves that there are three methods of obtaining cryojets known to date [3, 4].

The first method is based on the use of thermodynamic processes occurring in a subcooled liquid. The water temperature at a pressure of up to $200 \mathrm{MPa}$ can be lowered, for example, to $-20^{\circ} \mathrm{C}$. Therefore, during the release of a subcooled water jet from the nozzle under pressure into the atmosphere, part of that water turns into ice particles. This method of obtaining cryojets is recommended to be used at water pressure of at least $200 \mathrm{MPa}$, which allows it to be cooled to relatively low temperatures [3].

According to the second method, the crushed and sifted ice particles are fed into the high-speed water-jet with the ejection effect, as it occurs in the well-studied process of water abrasive jet forming. The technological process of obtaining a high-speed water-ice jet is based on previous obtaining of ice with the subsequent formation of a water-jet. This method, in comparison with the first one, is technologically more complicated, however, in our opinion, it is more promising, since it allows increasing the productivity of the material destruction due to the fact that the operation is carried out with ice particles, the temperature of which is below $-20^{\circ} \mathrm{C}$. This circumstance, as shown in [4], greatly affects the productivity of material destruction (for example, lowering the temperature of ice particles from $-30 \circ \mathrm{C}$ to $-80^{\circ} \mathrm{C}$ increases the destruction of solid material by approximately 4 times with all other conditions being equal).

The third method differs from the two previous ones in that liquid nitrogen is added into the water jet as a refrigerant, under the influence of which the liquid particles are formed in the water-jet inside the mixing chamber of the tool. As in the first case, after the subcooling we get a hydroabrasive jet at the nozzle, in which the abrasive component consists of small ice particles [3]. This method has a number of advantages in comparison with those discussed above. Thus, when liquid nitrogen enters the water-jet, there is no air in the mixing chamber, which is a negative factor for jet formation. The gaseous component of the jet is represented, in this case, by vapors of nitrogen (refrigerant) and water (the source of ice particles), i.e. the formation of ice particles occurs both in the liquid and in the gaseous phase of the jet.

From the point of view of cryojet cutting application in real tool constructions for the destruction of various materials, it is the third of the described cryojet formation methods that is the most promising one.

Analysis of cryojet cutting studies [5, 2, 6, 7, 8] shows that the main factors, defining and characterizing the process, can be divided into the following groups:

- hydraulic ones: water pressure P0 before the jet-forming nozzle, diameter d0 of the jetforming nozzle, flow velocity $\mathrm{V} 0$;

- geometric ones: length lкc and diameter dkc of the mixing chamber, diameter $\mathrm{d} \kappa$ and length $1 \kappa$ of the collimator;

- operational ones: speed Vח of the tool moving along the material, mass flow rate of nitrogen QN (diameter of the liquid nitrogen supply system orifice $\mathrm{dN}$ ), concentration of ice particles in the cryojet $\mathrm{c}$, distance 10 between the collimator cut and the rock surface; - mechanical properties of the material.

The depth of cut $h$, cutting side surface increment rate F0 and the specific energy consumption of the cutting process E0 should be taken as the main criteria for evaluating the cryojet cutting efficiency.

In order to carry out a number of experiments on the effect of the main factors, influencing cryojet cutting parameters, a bench unit consisting of a water pressure source, a cryojet tool, and workpiece positioning and moving system was developed.

Cryojet tool deserves special attention (fig. 1). The tool consists of the mixing chamber, inside of which there is a water jet-forming nozzle on its longitudinal axis, fed by water from the high-pressure source. In addition, the liquid nitrogen feed line is connected to the 
mixing chamber. The water, flowing from the jet-forming nozzle into the mixing chamber, carries the particles of liquid nitrogen and enters the collimator, where ice particles and final suspension cryojet are formed. All elements of the cryojet tool, subject to significant dynamic and thermal loads (jet-forming nozzle, collimator) are made of strong alloy, and also can be quickly replaced.

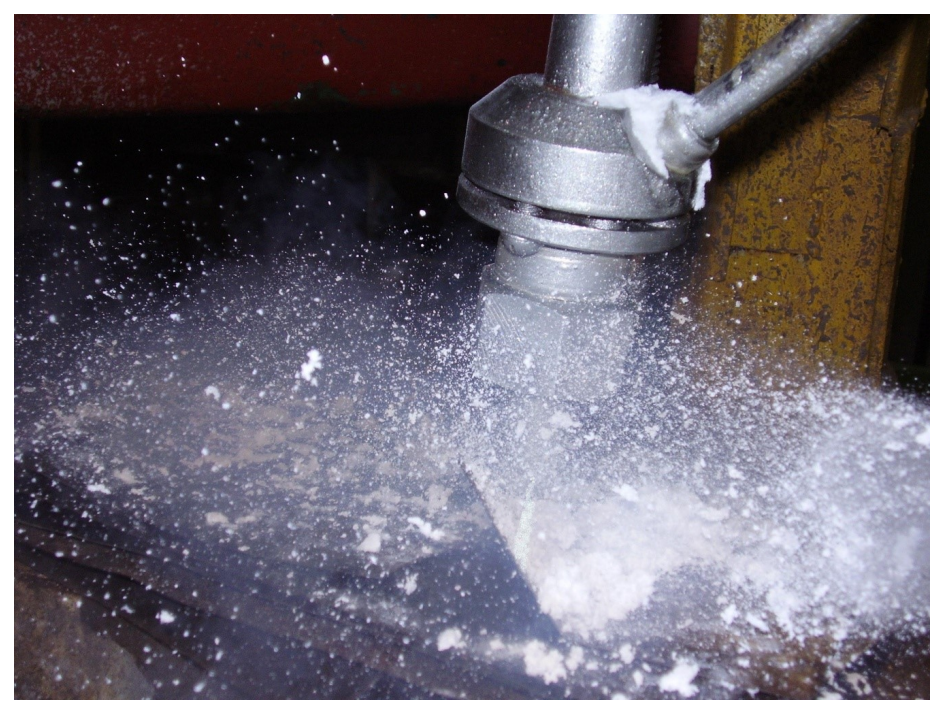

Fig. 1. Cryojet tool.

In order to study the influence of the mixing chamber geometry on jet saturation with ice particles, it was possible to change its internal diameter and chamber length by means of expansion sleeves.

As already mentioned, the depth of cut $\mathrm{h}$ depends on a number of factors, the main of which are: tool motion speed $\mathrm{V} \Pi$, water pressure $P_{0}$, Shore hardness index for material samples $\mathrm{S}$, distance from the collimator cut to the material sample 10, collimator and nozzle diameters ratio $\mathrm{d} \kappa /$ do, jet-forming nozzle hole diameter $d_{0}$.

Thus, the relationship between the cutting depth $\mathrm{h}$ and the cutting parameters can be written in the following form:

$$
\mathrm{h}=\mathrm{f}_{1}\left(\mathrm{~d}_{0}, \mathrm{P}_{0}, \mathrm{~V}_{\mathrm{\Pi}}, \mathrm{S}, \mathrm{l}_{0}, \mathrm{~d}_{\mathrm{K}} / \mathrm{d}_{0}\right),
$$

Investigation of the influence of each of these parameters on the cutting depth leads to the construction of curves that are difficult to use. Therefore, in order to obtain generalizing quantitative correspondences, we used a graphoanalytical method which allowed us to generalize the experimental data taking into account the internal qualitative and quantitative relationships between the parameters of the correspondence (1).

Among the constant factors are the following ones: 10, $\mathrm{d} \kappa / \mathrm{do}$.

Considering that some criteria did not change during the experiment, expression (1) will have the following form:

$$
\mathrm{h}=\mathrm{f}_{2}\left(\mathrm{~d}_{0}, \mathrm{P}_{0}, \mathrm{~V}_{\text {п }}, \mathrm{S}\right)
$$

Experimental data analysis by means of the multiple regression method allowed obtaining a general formula for the depth of cut:

$$
\mathrm{h}=6.9 \cdot 10^{7} \frac{\mathrm{P}_{0}^{0.7} \times \mathrm{d}_{0}^{2, .3}}{\mathrm{~S}^{1.69} \times \mathrm{V}_{\Pi}^{0.86}}
$$




\section{Conclusion}

Experimental data variation coefficient with respect to the calculated data was $K v a r=15,7$ $\%$, which indicates satisfactory congruence of the calculated and experimental data.

The obtained dependences enable us to carry out calculations, concerning the use of cryo jet cutting technology in the technological cycle of various enterprises, which will expand the field of hydro-jet technologies application in general.

\section{References}

1. V. A. Kravets, S. V. Rusakov, S. V. Volchkov, Light industry technology, 4, 129-132 (1985)

2. M. Hashish, C. M. Dunsky, The formation of cryogenic and abrasive-cryogenic jets (BDFF, Belgium, 2006)

3. K. A. Golovin, A. V. Polyakov, Mining information-analytical bulletin, 12, 252-255 (2004)

4. K. A. Golovin, K. V.Demin, G. V. Grigoriev, Methods of obtaining cryojets and prospects for their application for the destruction of rocks and other solid materials (Tula State University, Tula, 2002)

5. V. A. Brenner, A. B. Zhabin, A. E. Pushkarev, M. M. Schegolevsky, Hydro-jet technologies in industry. Hydro-abrasive cutting (Moscow State Mining University Publ., Moscow, 2003)

6. A. E. Pushkarev, Explanation and selection of the hydro-abrasive tool parameters of the mining machines' operation unites with the development of high-pressure equipment modules (Tula State University, Tula, 1999)

7. K. A. Golovin, D. N. Efremkov, R. A. Kovalev, A. B. Kopylov, Considering the dilatancy in describing the interaction of a high-speed jet with a rock mass (Tula State University, Tula, 2016)

8. I. V. Afonsky, K. A. Golovin, N. V. Kashkovsky, R. A. Kovalev, A. E. Pushkarev, Tula State University Nullitin. Technical sciences, 8:1, 52-56 (2015) 